\title{
Experiência religiosa: busca de uma definição
}

\author{
Mauro Martins Amatuzzi \\ Pontifícia Universidade Católica de Campinas
}

\begin{abstract}
Apresenta o estudo teórico, parte de uma pesquisa maior que visa descrever fenomenologicamente a experiência religiosa a partir de depoimentos pessoais. A experiência religiosa respeitável para o homem contemporâneo, seria aquela que não é vivida como uma defesa falaciosa face à fragmentação da experiência característica da época pós-moderna. Ela se apresenta como a consciência imediata de uma relação com o absolutamente transcendente, sem, contudo, que esse transcendente seja diretamente percebido em si mesmo. Ele é o polo oculto de uma relação que no entanto é vivida, e o é de uma forma intramundana. Essa experiência é de natureza tão radical que traz em seu bojo a possibilidade de uma resignificação do mundo. Deve ser entendida também como um processo onde sua própria compreensão vai evoluindo e se tornando mais adequada aos olhos do sujeito que a vivencia.

Palavas-chave: experiência religiosa, religião, magia, fé.
\end{abstract}

\begin{abstract}
Religious experience: search for definition

Theoretical study that is the first part of a more encompassing research aiming to describe phenomenologicaly the religious experience basing on personal reports. Religious experience, in the real sense of the word, is something not lived as a delusive defense for the characteristic fragmentation of the experience in the post-modern era, but presents itself as a immediate awareness of a relationship with something that is conceived as absolutely transcendent that, however, is not directly perceived in itself. This transcendency is the hidden side of a relationship that, however, is experienced as a relationship in the everyday life. The extreme nature of this experience makes possible changes in the person world meanings. It must also to be understood as a process in which its own comprehension becomes more and more appropriate to the person who experiences it.

Key-words: religious experience, religion, magic, faith.
\end{abstract}

Este artigo corresponde à primeira parte de uma pesquisa que teve como objetivo primeiro descrever a natureza da experiência religiosa a partir de depoimentos pessoais. A complexidade do assunto, no entanto, exigiu um equacionamento prévio da questão em termos teóricos. Resultados parciais dessa busca teórica já foram publicados sob forma de comunicação (Ama-

Endereço para correspondência: Rua Luverci Pereira de Souza, 1656, Cidade Universitária, CEP 13084-031, Campinas, SP, Fone: (019) 239-2635. tuzzi, 1996). Retomamos agora esse assunto situando-o numa abrangência maior, e ampliando aquela comunicação. Em um artigo que se seguirá a esse traremos a análise de um depoimento escolhido entre os que foram colhidos.

O interesse pela espiritualidade e experiência religiosa, e suas relações com a Psicologia, tem aumentado ultimamente como demonstram as referências a artigos publicados em revistas científicas, ou a livros, cadastrados nos últimos números da Psychological Abstracts. Helminiak (1996) 
menciona que um levantamento a partir de 1986 até a data em que foi feito seu artigo, dá acesso a mais de mil referências cadastradas nos termos spirituality e spiritual. Refazendo esse levantamento atualmente, para o período de 1991 a março de 1997, encontrei as seguintes quantidades: para religion 2043 referências, para religious 3329, para spirituality 751, para spiritual 1123 , para God 604 referências (!), para religious + experience 142 referências e para God + experience 118 referências. Em nosso próximo artigo mencionaremos alguns desses estudos.

Por outro lado, num trabalho recente meu com Psicologia na comunidade (Amatuzzi, 1996) ficou clara a importância do sentimento religioso, ou da experiência religiosa, nas atitudes pessoais em relação ao desenvolvimento humano, e portanto para os agentes que prestam serviços nesse campo. Isso que parece particularmente válido no contexto de comunidades latino-americanas, é confirmado também pela experiência de quem atende pessoas em psicoterapia: quase sempre que se chega aos pontos centrais da organização da personalidade, ou ao "centro da pessoa" como diria Buber, surge o tema religioso de forma ao menos implícita.

\section{Experiência autêntica?}

Miklós Tomka, professor de Sociologia Religiosa e, em 1989, presidente do Hungarian Religious Research Centre, em artigo recente (Tomka,1997) caracteriza a fragmentação do mundo da experiência na época moderna, permitindo-nos situar a experiência religiosa em um contexto cultural mais abangente.
Antes da modernidade, segundo ele, predominava uma visão de mundo imutável, existindo sob condições constantes. É bem verdade que no espaço cultural greco-romano ou judeo-cristão chegou a surgir uma consciência histórica. Não obstante, a lentidão do desenvolvimento cuidava que se experimentasse uma sensação de imutabilidade e de condições basicamente constantes. As condições técnicas disponíveis limitavam as possibilidades da vida - e tornavam-nas previsíveis. As relações sociais eram fixas e normalmente não questionadas. Sua rede era capaz de controlar e vigiar a vida na sua totalidade, e ao mesmo tempo de oferecer proteção e segurança pessoal. Vivia-se assim num mundo estável, unificado e, em certo sentido, fechado. A cultura recebida dos ancestrais era transmitida e imposta pelo sistema social organizado, contribuindo por sua parte para a integração e para a unidade da comunidade (Tomka, 1997, p.12-13).

Nesse contexto a religião tinha uma função de apoio adicional dessa visão mais ou menos fechada, face aos desafios do desconhecido e do inexplicado bem como das contradições e das contrariedades da vida (id., p.1314). O mundo fragmentado das experiências foi cimentado pela fé religiosa e pela experiência religiosa (id., p.14). Poderíamos dizer nós, quem sabe, comentando o pensamento de Tomka, que fé religiosa (enquanto adesão a um sistema) e experiência religiosa (enquanto experiência) se apoiavam e se implementavam mutuamente.

Segundo Tomka, uma das características do mundo que se seguiu a esse preparando o advento da era moderna, foi a ampliação dos horizontes espaço-temporais. 
Os horizontes da experiência e da apreensão do mundo começaram a dilatar-se ao infinito. As grandes descobertas fizeram de todo o globo terrestre o espaço vital do homem. Conhecimento e sentido da realidade desligaram-se das vivências pessoaise se tornaram independentes. As ciências passaram a ser os protagonistas da cultura moderna (id., p.15).

O mundo foi perdendo em unidade e ganhando em diversidade. No entanto um grande esforço foi dispendido em se preservar a unidade, e, na linha do tempo, uma continuidade. Surgiu então a idéia de evolução: mudança e diversidade poderam ser compreendidos, num outro tipo de unidade, como fases de um único processo. $A$ idéia de evolução transmitiu não apenas o conceito de crescimento, de enriquecimento, de surgimento de algo novo, mas também de um evoluir sobre o mesmo tronco, de uma conexão que não sofreu ruptura (id., p.16). No plano político, também, a expansão do mundo europeu para outros continentes foi vista como empenho missionário cristão, e depois, com o aumento das relações entre as nações e culturas, amadureceu a visão da comunidade de destino da humanidade (id., p.17): de novo a preservação da unidade. Mas a ordem divina do mundo foi substituída por regras cósmicas e universais, e não obstante inteiramente mundanas. Em lugar do Deus que conserva e dirige os mundos entra o homem que domina as leis (id., p.18). Tudo isso corresponde à época moderna.

O que há de novo em nosso mundo atual, para Tomka, em nossa época pósmoderna, é que apesar de toda coerência lógica, nosso mundo de experiências se decompõe em fragmentos (id., p.18). E ele menciona a crescente mobilidade, a independência dos subsistemas em que vivemos, o pluralismo, a convivência de culturas (muitas vezes denominadas por suas diferentes tradições religiosas). Dando continuidade à movimentação das grandes viagens e descobertas, temos agora a mobilidade social e geográfica em função do trabalho principalmente. A mudança e a pluralidade passaram a ser as marcas de nosso mundo. Daí algumas consequências importantes: o espaço ambiente e o mundo perdem sua unidade orgânica; o passado já não nos traz evidências diante da multiplicidade de alternativas; a pessoa fica dividida nas diferentes áreas em que sua experiência se desenrola. São aspectos da fragmentação de nosso mundo. Diante desse espetáculo ninguém mais pode se dar ao luxo de considerar a própria tradição como a única correta. (...) A gama de concepções do mundo e das posições religiosas possíveis torna-se sempre mais rica (id., p.22).

Essa experiência fragmentada da vida produz reações diferentes. A primeira delas: o homem passa a ser simplesmente um expectador (id., p.20). Um sentimento de impotência acaba produzindo um fatalismo nessa não participação. Embora a ciência e a técnica continuem com seu prestígio (e, juntamente com elas, a nova casta sacerdotal de especialistas), já não se acredita talvez mais em ninguém, e se tenta manter os controles através de regras pragmáticas. A rotina é transformada numa vaca sagrada, porque não existe nenhuma outra coisa (ou outra pessoa) que pudesse ser sagrada para alguém (id., p.23). 
A segunda reação mencionada por Tomka é a rejeição do mundo que está aí. Por exemplo através da criação de ídolos particulares. A própria pessoa, o poder, a carreira profissional, o sexo e o prazer passam a ser os centros aos quais tudo é referido. Outros se afastam de qualquer participação mais ativa em termos políticos, e recolhem-se à vida privada passando a ser meros consumidores. $\mathrm{E}$ carregando sempre a sensação de estarem sendo enganados (id., p.24). Outros ainda podem ser levados a construir um mundo à parte juntamente com um sub-grupo cultural com o qual se identifiquem mais. Tomka fala também de um aspecto agressivo de que se pode revestir essa rejeição, seja individualmente, seja como grupo, face àquilo que foi rejeitado, ou àqueles que o foram.

A terceira reação, que parece ser a mais positiva, é descrita por Tomka em termos de aceitação da fragmentação como ela se mostra e tentativa de lidar com ela a partir de uma integração pessoal.

Apesar da crescente complexidade do mundo que a envolve, a pessoa pode preservar sua integridade. Para seu comportamento ela pode impor como medida seus próprios valores e critérios. Porém para isso ela necessita de uma decisão que nenhuma instância pode tomarem seu lugar. E tem que ter consciência da transitoriedade desta decisão (id., p.26).

E ele comenta isso enfatizando dois pontos. Um, é que embora a fragmentação da experiência não possa ser superada inteiramente no plano do conhecimento, é possível encontrar para ela uma moldura que a sustente, e isso seja no relacionamento entre as pessoas (e ele cita aqui o princípio dialógico de Buber), seja também na relação religiosa entre Deus e sua imagem terrestre. E o outro ponto se expressa nessas palavras com as quais ele termina seu artigo: a fragmentação da experiência da vida só pode ser enfrentada por pessoas que possuem capacidade de decisão (id., p.27). - Uma relação humana pessoal e profunda e uma relação religiosa que não negue o humano, podem ser atualmente apoios da pessoa face a experiência da fragmentação de seu mundo. E ainda é necessária uma estrutura pessoalforte, que se mostra como capacidade de decisão face a uma ausência de direção única por parte do mundo e face à resistência do sistema diante de afirmações pessoais.

Podemos concluir que, para Tomka, a experiência religiosa na linha das duas primeiras reações à fragmentação do mundo (reação de negação, tornando-se expectador do mundo; e reação de rejeição, criando um mundo à parte) seriam experiências religiosas mais defensivas. É na terceira reação à fragmentação do mundo (aceitação do mundo como se nos apresenta e posicionamento face a ele a partir de um polo pessoal de integração) que se poderia pensar em uma experiência religiosa mais autêntica em nossa época pós-moderna. Estaria ele com isso relegando à inautenticidade tanto as formas de religiosidade anteriores à modernidade, quanto as que decorrem das reações de negação e rejeição do mundo atual? Tomka não explicita isso, mas, creio eu, sugere que, se a experiência religiosa, naquelas situações, podia se sustentar apesar de a religião ter uma função de apoio ao sistema, isso, em nosso contexto atual, já não é mais possível. Ou seja, o 
testemunho religioso a ser considerado por uma pessoa que se faz presente a nosso mundo atual, há de ser o daquele que aceita o espetáculo deste mundo como ele se manifesta, e assim mesmo toma posição ativa e participante face a ele, a partir de um centro pessoal de integração.

Pudemos assim situar uma possível respeitabilidade dessa experiência em nosso mundo. Mas o que é essa experiência em si mesma? É preciso, porém, antes, esclarecer em que sentido estamos tomando alguns conceitos.

\section{Conhecimento e experiência}

Por que falamos de experiência religiosa e não de conhecimento religioso? Qual a diferença entre conhecimento e experiência? O termo experiência normalmente é usado para designar não qualquer conhecimento, mas aquele obtido na prática, na lida concreta com objetos particulares, e não nos livros ou no mero exercício dedutivo da razão raciocinante. E a partir daí ele pode ser usado para designar o conhecimento que existe na relação com o objeto, que faz parte desta relação e que lhe constitui a consciência imediata. Enquanto tal inclue dois aspectos: consciência do contato, e consciência de significados aí contidos implicitamente. Um "homem de experiência" é uma pessoa que "sabe" muito, a partir da vida, por ter passado por muitos acontecimentos e reagido a eles. Mas isso não significa que ele possa dar boas aulas sobre isso. Significa, isto sim, que ele tem mais condições de reagir adequadamente diante de situações análogas. Ou seja, a experiência é um conhecimento imediato, e ao mesmo tempo transporta um conhecimento tácito. Isso é diferente de uma dedução intelectual, embora possa originar uma reflexão ou uma elaboração posterior (ver, por exemplo, Brugger,1987; Vaz, 1986; Meslin, 1992).

Poderíamos também dizer que falamos de experiência para não nos referirmos basicamente às elaborações intelectuais produzidas enquanto em si mesmas consideradas, mas à base que as precede, e que é a única responsável pela ligação dessas elaborações com a realidade. A partir daí o termo se aplica também às elaborações, mas não enquanto isoladas em si mesmas, e sim em sua relação com aquela base; portanto enquanto impregnadas de realidade. O que guia as elaborações baseadas na experiência é muito mais a própria realidade do que a lógica das ilações formais.

Uma entrevista que pretende captar a experiência vivida, deve clarear para a pessoa entrevistada os significados mais originais de sua experiência, não por imposição de estruturas de pensamento, mas por um retorno à origem propriamente experiencial da experiência, como que conferindo suas posteriores elaborações com essa origem.

O termo experiência religiosa se refere pois ao aspecto imediato, autêntico, do conhecimento religioso, enquanto consciência do contato e de significações potenciais, e não a elaborações intelectuais consideradas enquanto isoladas de um contato de realidade básico. 


\section{Experiência religiosa $\mathrm{e}$ experiência de Deus}

Segundo Henrique de Lima Vaz a experiência religiosa é uma experiência do Sagrado e a experiência de Deusé uma experiência do Sentido (Vaz, 1986, 249). Sobre a primeira ele explica: Na experiência do Sagrado o pólo da presença define-se pela particularidade de um fenômeno, cujas características provocam, no pólo da consciência, essas formas de sentimento e emoção que formam como que um halo em torno do núcleo cognoscitivo da experiência e que análises clássicas como as de Rudolf Otto procuram descrever (p. 249). E ele está se referindo, com certeza, ao temor reverencial da experiência do Sagrado. Mais adiante ele esclarece:

Se dissemos que a experiência religiosa ou experiência do Sagrado não é necessariamente uma experiência de Deus é porque o religioso ou o Sagrado resultam da função simbolizante do homem nesse terreno que se estende entre o facínio e o temor do que é incompreensível ou misterioso. Todas as zonas de interrogação e espanto (...) do homem e do mundo são matéria de experiências religiosas ou sacralizantes (p.250).

Ou seja, a experiência do Sagrado se dá face ao desconhecido e misterioso, manifestando-se em eventos particulares, provocando interrogação ou espanto, e sendo expresso numa linguagem simbólica. Mais adiante ele dirá que a característica essencial da experiência religiosa como experiência do Sagrado (...) éa transgressão do histórico e a passagem a um espaço e a um tempo mitogenéticos (onde o mito nasce necessariamente como discurso sobre o Sagrado) (p.254).

E quanto à experiência do Sentido, ele diz: o que caracteriza a experiência de Deus é que ela experimenta, nesse espaço [circunscrito pelos limites do mundo, do outro e do eu], uma presença onipresente, a presença mesma do Sentido radical (p.252). Ou seja, no espaço limitado da experiência humana enquanto experiência das coisas do mundo, das relações interpessoais, e das relações consigo mesmo, experimentamos uma presença que está em toda parte e da qual depende o sentido último das coisas. E ele diz que é uma experiência absolutamente única pois se trata de uma presença que não se desvela. $\mathrm{E}$ continua:

O desvelamento de uma presença no espaço da experiência é sempre o recorte de uma particularidade no fundo indeterminado dos sentidos possiveis. Mas na experiência do Sentido radical, estamos diante de uma presença analógica (na acep̧̧ão rigorosamente filosófica do termo) que torna possível o desvelamento de toda presença particular. Com efeito, nenhuma presença particular pode, por definição, ocupar o campo total do sentido. Por isso mesmo o Sentido radical, como presença onipresente, érigorosamente transcendente a toda presença particular. E como as presenças particulares não se somam numa totalidade de sentido, o Sentido radical é a um tempo presente e absolutamente transcendente. No entanto ele não é inexprimível ou inefável e eis por que podemos falar de uma experiência de Deus (p.252-253). 
Em suma, a experiência do Sagrado (experiência religiosa) se dá a partir de contatos com o desconhecido e misterioso, em acontecimentos particulares, provocando interrogação e espanto, gerando uma simbolização diferente da cotidiana, numa linguagem de outra ordem, pois nos transporta para um tempo e um espaço totalmente outros que o ordinário, um tempo e um espaço mitológicos. Poderíamos dizer que essa experiência não é mediada pela linguagem ou atitude simbolizante da ciência, hoje mais comum e mais eficaz no controle social. - E a experiência do Sentido radical (experiência de Deus) se dá no espaço da experiência humana comum do mundo, das relações inter-humanas, e da relação consigo mesmo, como uma forma de contato com uma presença transcendente, que está em toda parte, e que confere um sentido último a todas as presenças particulares, e que é passível de ser expressa na linguagem especificamente humana da expressão do sentido (e portanto racional).

Embora a rigor distintas, Vaz considera que essas experiências de fato se misturam historicamente: a experiência religiosa foi expressa frequentemente em termos de uma teologia, isto é, articulada com uma experiência de Deus, e esta, por sua vez, foi freqüentemente associada a uma religião.

Meslin (1992), no entanto, não radicaliza a diferença entre o Sagrado e o Divino, apresentando-os de forma bem mais articulada. Formulemos em 4 pontos suas principais ponderações.

1) O sagrado parece aos homens o lugar onde reside uma força eficaz, manifestação de um poder divino, uma energia substancial e criadora, que muitas vezes lhe é incompreensi- vel (p.79-80), diz ele, mostrando de início uma essencial relação entre o sagrado e o divino.

2) É justamente por manifestar esse essa força, passível de ser temida ou julgada perigosa, que os homens pretendem captaresse poder na prática concreta de sua sensibilidade como na de ações rituais (p.80). De qualquer forma o homem espera pois dessas coisas sagradas que manifestam a seus olhos o divino, que elas exerçam uma influência sobre sua própria vida e que elas aí introduzam a ordem, a consistência, a coesão daquilo que ele julga ser o real (p.81). O poder vislumbrado nas experiências do sagrado, envolve profundamente o ser humano que se relaciona com ele.

3) A própria vida assim experimentada, constitui para o homem o lugar e o meio de experiências mediatas do divino, ou seja, hierofanias (p.81). - A partir daí Meslin pode afirmar que

não é por essência, mas segundo a consciência do homem, que o sagrado e o profano existem. O objeto sagrado é sempre da mesma natureza que as outras realidades do mundo. Ele nada tem de absoluto em si. Só a relação que o homem pode estabelecer ent:e esse objeto e um "Incondicionado misterioso e transcendente", para tomarmos a fórmula de P.Tillich em sua "Filosofia da Religião", Ihe confere a qualidade de sagrado (p.81-82).

Ou seja, o sagrado é alguma coisa mundana, que tem seu lugar natural neste mundo, porém percebido enquanto na sua relação com o divino, e portanto enquanto manifestação desse divino. 
4) Que coisas são escolhidas como manifestação do divino, ou melhor, em que coisas incide a percepção dessa especial relação? Isso, diz Meslin, é histórico, e portanto sujeito a contínuos deslocamentos (p.8283). Mas ao mesmo tempo, como parece ser o caso atual,

esse deslocamento do sagrado pode ser vivido como uma reação violenta contra uma certa ordem moral ou política e contra o caráter por demais técnico de nossas sociedades pósindustriais. Ele se torna assim uma contracultura (p.83).

Num texto de síntese, como que reunindo esses pontos, diz Meslin:

\section{O sagradoé sempre o lugar me-} diador entre o humano profano e o divino, porque ele é como o eco, ou como o reflexo, do divino no mundo do homem. Sob as múltiplas fisionomias que a história lhe empresta, o sagrado é pois esta parte do mundo que o homem associa, mais ou menos simbolicamente, à experiência que ele pode ter do divino, essa realidade transcendente que lhe fica em parte sempre oculta (p.84).

A expressão experiência religiosa, então, parece ser em si contraditória, pois o religioso (aquele transcendente) é algo que terá sempre um aspecto oculto. Como falar então de experiência (conhecimento ou consciência imediata)? Aqui Meslin segue de perto as pistas traçadas por Friedrich Schleiermacher e Rudolf Otto, das quais destacamos também 4 pontos.
1) A experiência religiosa é uma captação do Infinito divino, do eterno no mortal (p.94). Portanto, diríamos nós, experiência de uma relação com um transcendente, o qual, no entanto, não é diretamente visível: de alguma forma, uma experiência ao mesmo tempo que direta e imediata, também indireta ou mediata.

2) A experiência religiosa consiste pois em conhecer a própria vida no sentimento imediato deste ser infinito e eterno (p.95). E esse sentimento aqui não é algo que se oponha a um pensamento, mas se refere ao caráter imediato da consciência e não a uma consciência reflexiva (p.96). Diríamos nós: o polo transcendente da relação não é diretamente visto, mas a consciência da relação é direta. - Mas de quê sentimento se trata então? Para Schleiermacher, segundo Meslin, é o sentimento de absoluta dependência.

O sentimento de dependência absoluta é a forma pela qual se manifesta a consciência que temos de termos Deus em nós, de estarmos em relação com ele, de sentirmos sua presença em nós. Isso é a experiência religiosa viva. (p.97)

3) Essa experiência tem uma expressão conceitual objetiva na idéia de Deus.

Se esse sentimento de dependência absoluta é identificado com a consciência de estar em relação com Deus, isso significa que existe uma relação entre experiência e conceitualização. A idéia de Deus é assim a expressão do sentimento de dependência; ela constitui o primeiro resultado reflexivo, a primeira conceitualização da consciência religiosa. Por- 
tanto é a experiência que o homem tem de seu ser criado que está na origem de toda a idéia de Deus. (p.97)

Eu acrescentaria que podemos entender porque o budismo primitivo, que prescinde da idéia de Deus, tenha se apresentado originalmente não como uma religião mas como uma medicina. E que, muito cedo, a radicalidade de tal medicina acabou possibilitando verdadeiras experiências do sagrado.

4) Ocorre aqui uma possível bifurcação. A própria experiência só deslancha se houver uma adesão ao polo oculto (embora pressentido) da relação vivenciada. Segundo Meslin, o que Schleiermacher sentiu e afirmou com precisão é que diante do fenômeno religioso a única atitude possível era se abrir - para melhor compreendê-lo - para um real que é portador de um sentimen to oculto e ao mesmo tempo revelado ao homem (p.98). Antes, com R.Otto, ele dizia: a experiência religiosa (...) se torna a resposta do homem a esse poder misterioso, a esse divino que se revela (p.90).

O termo "deslanchar" (dar andamento, partir), não é de Meslin, mas não vejo como evitá-lo. Com efeito remete ao aspecto dinâmico e processual da experiência religiosa. Ela é uma experiência que começa, mas só pode ir adiante com um envolvimento do sujeito.

Experiência religiosa, então, é uma expressão que vem a designar a consciência imediata de uma relação com um transcendente, que no entanto não se manifesta diretamente, conservando sempre uma face oculta.

\section{A inquietação religiosa}

Também parece importante para esta pesquisa, diferenciar a experiência religiosa propriamente dita, da inquietação religio$s a$. Essa última é a experiência das dimensões do vazio que nos habita, seja ele aceito como mola propulsora de uma busca que não sabemos onde vai dar, seja ele negado por um raciocínio simples, segundo o qual se trataria no fundo de uma sensação ilusória decorrente basicamente de nossa própria capacidade de pensamento abstrato. Dessa inquietação religiosa é possível, com certeza, fazer toda uma fenomenologia (ver, por exemplo, Mahfoud, 1997, e Valentini, 1997). Contudo é uma inquietação que se passa toda dentro de nós, ainda que provocada por eventos externos. O que se busca neste estudo é justamente a experiência de algo que nos remeta para fora, o que pode até pressupor aquela inquietação, mas não é a mesma coisa. É efetivamente uma relação ou um encontro.

\section{Experiência religiosa como encontro}

Dois pequenos livros de Martin Buber podem servir de base para descrevermos a experiência religiosa no sentido em que a tomamos aqui. O primeiro deles, tem como título "Eclipse de Deus" (Buber, 1984), e foi escrito basicamente a partir de conferências pronunciadas nos Estados Unidos em 1951. E o outro reune pequenos manuscritos autobiográficos sob o título de "Encontro: fragmentos autobiográficos" (Buber, 1991). Eis alguns pontos descritivos que podemos daí retirar: 
1) Em primeiro lugar trata-se de uma experiência, e isto quer dizer que há nela uma essencial referência a uma realidade, um contato com algo externo ao sujeito que experiencia, um encontro vivo com uma presença.

Um belo trecho de Buber que ilustra esse ponto é o seguinte:

Em algumas épocas aquilo que os homens 'creem' como algo absolutamente independente deles mesmos, é uma realidade com a qual se encontram em relação viva, mesmo sabendo que só podem construir dela uma representação totalmente inadequada. Já em outras épocas, pelo contrário, substitui a essa realidade uma representação variável que os homens 'possuem', e que portanto podem manipular, ou então somente um resíduo dessa representação, um conceito que conserva apenas tênues vestígios da imagem original. (Buber, 1984, p.15)

Ele opõe aqui um crer numa realidade independente, a um possuir uma representação ou resíduo de representação. No primeiro caso há uma relação viva, no segundo, apenas idéias a respeito, mesmo quando a essas idéias se possa atribuir uma existência real (cf.id.p.15).

2) Isto não quer dizer que só existam as grandes revelações, solenes e dizendo respeito à vida toda ou à vida de uma coletividade, como experiência religiosa. Também na vida cotidiana elas podem ocorrer, e dizendo respeito à própria vida cotidiana da pessoa.

Buber, é muito suscinto quanto a isso, mas deixa claro que a relação religiosa pode se dar na vida diária, naqueles mo- mentos em que adquirimos consciência da realidade absolutamente independente de nós, seja como poder, seja como glória, ou então nas horas de grande revelação ... das quais nos chegaram apenas relatos entrecortados (Buber, 1984, p.17).

3) A experiência religiosa tem por objeto o transcendente, o divino, o absolutamente independente de nós, percebido enquanto poder e glória.

O absolutamente independente de nós é uma expressão que volta com bastante freqüência nesses textos de Buber, mas também o divino, e percebido enquanto poder e glória, ou como o transcendente.

4) A experiência religiosa se dá no contexto concreto da vida, com suas ambiguidades, contradições e anseio de salvação, e não no contexto acéptico das idéias, como se fosse apenas um entendimento novo.

Comentando o pensamento de Bergson, eis o que ele afirma:

As experiências religiosas cruciais do homem não acontecem numa esfera onde a energia criadora opera sem contradição, mas em uma esfera onde habitam lado a lado o bem e o mal, o desespero e a esperança, o poder de destruição e o poder de renascimento. A força divina que o homem encontra realmente na vida não sobrevoa o demoníaco, mas o penetra. Limitar Deus a uma função produ tora é eliminá-lo do mundo em que vivemos, um mundo cheio de contradições que queimam e do anseio de salvação (Buber, 1984, p.23).

5) Trata-se também de uma experiência que tem uma repercussão direta na vida da 
pessoa. Ela é tal que transforma ou modifica a vida.

Um texto que pode ser evocado aqui é um comentário a partir de Hegel:

Já não se encontra no mundo de Hegel (se deixarmos de lado suas obras de juventude, dotadas de uma orientação completamente diferente) a realidade de uma visão ou de um contato que determina diretamente nossa existência, o qual era uma certeza fundamental para pensadores como Platão e Plotino, Descartes e Leibnitz (destaques meus) (id.p.20).

6) Há qualidades características dessa experiência. Um delas é que ela é $u m a$ experiência abrumadora, isto é, que faz vivenciar uma realidade totalmente diferente do cotidiano, da qual resulta também um olhar totalmente diferente sobre si mesmo ou sobre o significado da própria vida. Diante da grandeza do experienciado, a pessoa se sente como nublada, infinitamente pequena, e entregue.

Quando falamos desse encontro, nossas palavras devem dar conta dessa como proximidade corporal que torna o homem obscurecido em seus encontros com o divino, seja porque o encham de temor reverencial, seja porque o transportem de arrebatamento, ou simplesmente porque o brindem com um guia (Buber, 1984,p.16).

7) Outra dessas qualidades é que ela se dá na reciprocidade, isto é, no envolvimento pessoal e total da pessoa face a um Outro. A forma concreta como se dá essa reciprocidade é a de um diálogo onde a "voz divina" nos fala através de acontecimentos, e res- pondemos a ela por aquilo que fazemos ou deixamos de fazer.

Se a realidade dessa relação, para Buber, é seu aspecto supremo (como dissemos em nosso primeiro ponto), seu núcleo é a forma concreta como ele se dá. E esse núcleo ele o descreve exatamente como um diálogo entre Deus e o homem - a voz divina falando no que acontece ao homem, e o homem respondendo pelo faz ou deixa de fazer (Buber, 1984, p.19).

Em outro lugar ele diz:é no próprio encontro que nos vemos confrontados com algo (...) que exige reciprocidade, um $\mathrm{Tu}$ primário (Buber, id.p.16-17). E diz ainda: à diferença dos princípios e ideais, o que está face ao homem não pode ser descrito como um Isso, mas pode ser invocado e alcançado como um $\mathrm{Tu}$ (id.p.25).

8) Como para qualquer experiência, podemos formar conceitos, representações, imagens dela e seu objeto. Contudo, em virtude daquilo que esta experiência é enquanto contato com algo absolutamente independente, que envolve e transcende totalmente, essas imagens e representações só podem ser radicalmente imperfeitas e inadequadas, e temos condições de nos dar conta disso.

Em um determinado momento de sua reflexão, Buber está se perguntando se um conceito de Deus ajuda ou prejudica a experiência; se uma apreensão intelectual do divino, prejudica necessariamente a relação religiosa concreta (p.16). E ele responde:

Tudo depende da medida em que esse conceito de Deus possa fazer justiça à realidade por ele indicada, fazer-lhe justiça enquanto realidade. Quanto mais abstrato for o conceito, tanto mais requererá ser equilibrado 
pela experiência viva com a qual está intimamente ligado, e isso mais do que estar concatenado com um sistema intelectual (id.p.16).

Ele havia dito antes (no trecho já citado no ponto 1) que nas experiências religiosas mais autênticas, as pessoas sabem que só podem construir uma representação totalmente inadequada da realidade com a qual, no entanto, estão em relação viva (id.p.15).

9) Para melhor fazer justiça à realidade desse contato, na sua expressão o aspecto intelectual dos conceitos deve ser complementado pelos aspectos descritivos concretos da experiência efetiva, os quais, por se radicarem no sujeito que experiencia, não podem deixar de ser também antropomórficos.

A continuação do trecho citado no item 8, é a seguinte:

Quanto mais distante do antropomorfismo parece um conceito, tanto mais deve ser organicamente completado por uma expressão desta (...) proximidade corporal que torna o homem obscurecido em seus encontros com o divino (...). O antropormorfismo reflete sempre nossa necessidade de preservar a qualidade concreta manifestada no encontro; contudo, nem sequer esta necessidade é sua verdadeira raiz: é no próprio encontro que nos vemos confrontados com algo abrumadoramente antropomórfico, algo que exige reciprocidade, $\mathrm{um} \mathrm{Tu}$ primário (id.p.16-17).

10) A experiência religiosa abre a pessoa para um mundo inteiramente novo e diferente do cotidiano, do qual só é possí- vel dar conta a partir de dentro dele mesmo. Isso equivale a dizer que fica preservada a possibilidade de uma recusa.

Refletindo sobre a obscuridade de Deus em nossa época, o eclipse de Deus, Buber diz: Quem se recusa a se submeter à realidade da transcendência como tal, como nosso vis-a-vis, contribui para a responsabilidade humana do eclipse (id.p.25).

A recusa é possível, pois, e ela se radica no fato de que só podemos dar conta da novidade desta experiência, a partir dela mesma, como ocorre em um encontro.

11) Como características negativas da experiência religiosa devemos dizer que ela não se confunde com a magia, nem com a gnose, e nem com a subjetivização da fé. Essas três coisas correspondem a atitudes pseudo-religiosas.

O que caracteriza a magia como atitude humana, é o impulso de controlar. O objeto da relação mágica é, pois, algo que, de alguma forma, pretendo dominar. Ora, a genuína relação religiosa é totalmente diferente disso. A relação que se constitui nela é muito mais de submissão total, de temor reverencial, e depois de amor, do que de controle. $\mathrm{O}$ objeto da experiência mágica não pode ser o mesmo que o da experiência religiosa. O objeto da experiência mágica é controlável, o da experiência religiosa é justamente o que não é passível de controle.

Desde que os homens encontraram os primeiros nomes para o eternamente inominado, em todos os idiomas os nomeados com esta palavra têm sido seres transcendentes, (...) não objetos conhecíveis, embora adquiríssemos consciência deles como (...) em relação conosco (...). Isso dife- 
renciou sempre religião de magia, pois já não se podia crer como sendo deus, alguma coisa que o homem acreditava ter conjurado, (...) [e que] havia se convertido num feixe de poderes que misteriosos conhecimentos e forças humanas podiam anular. Quem conjurava já não escutava a palavra, e nem despertava nele resposta alguma; e mesmo quando recitava uma prece, já não orava (Buber, 1984, p. 69).

E em outro lugar ele diz:

Desde os temipos mais antigos a realidade da relação de fé, a posição do homem ante a face de Deus desenvolvendo-se no mundo como um diálogo, foi ameaçada pelo impulso de controlar o poder do que está mais além. Em vez de entender os acontecimentos como invocações que nos propõem exigências, desejamos ser nós que exigimos, sem ter que escutar (Buber, 1984, p.110).

Quanto à atitude gnóstica, Buber considera que ela é até mais anti-religiosa que o próprio ateismo. Para ele essa atitude pretende desvendar os mistérios divinos, transformando-os assim em algo a nosso alcance, e, portanto, em nossa medida. $\mathrm{O}$ objeto de tal atitude também não pode ser o que se revela livremente como um outro. Trata-se de uma outra contrapartida pseudoreligiosa da relação de fé (Id., p.110).

A deturpação maior e mais atual da genuína relação religiosa, no entanto, para Buber, é a subjetivização da fé. Esta é uma atitude que penetra até a profundidade mais íntima da vida religiosa (p.111). Refere-se ele a uma atitude de tal forma reflexiva que re- presenta um bloqueio da espontaneidade do eu face ao outro que acaba impedindo um contato com qualquer tipo de presença verdadeira. Mas se o objeto com o qual se entra em relação com a verdadeira experiência de fé é justamente essa Presença Inominável, a atitude reflexiva acaba ficando com as palavras e perdendo a coisa mesma. A subjetivização da fé elimina o encontro.

O conhecimento subjetivo que alguém que se volta para alguma coisa, tem de seu próprio voltar-se para essa coisa, esse refreamento do Eu que não en tra em ação com o resto da pessoa, de um Eu para o qual a ação é um objeto - tudo isso significa a desapropriação do momento, a perda da espontaneidade. (...) Quem não está presente não pode perceber Presença alguma (Buber, 1984, p.111).

O que está em questão aqui é a disposição do homem inteiro em aceitar esta Presença, a simples espontaneidade, sem reservas, em voltar-se para ela (Id., p.111).

Se quiséssemos formular, então, estas características negativas da genuína experiência religiosa, tiradas dessas comparações, poderíamos dizer que ela não é a experiência que toma consistência no interior de uma tentativa de controle de poderes externos (não se identifica com a magia), ou no interior da redução do mistério a algo a nosso alcance e em nossa medida (não se identifica com a gnose), e nem tampouco é aquela que é possível com reservas, sem uma entrega total da pessoa (não se identifica com o conhecimento reflexivo de um apegar-se a um deus). 
12) Há lugar para se falar de uma depuração da experiência religiosa, no que diz respeito aos conceitos ou noções através das quais nos damos conta dela. Eles podem evoluir no sentido de maior fidelidade ao vivenciado. E na medida em que eles participam da configuração global da experiência, esta pode vir a ser vivenciada de forma mais ou menos plena ou genuína. Enquanto inserida numa dinâmica dialógica de vida, ou seja, enquanto processo, a experiência religiosa se clarifica, e nessa medida pode também purificar a resposta humana.

No outro pequeno livro chamado "Encontro: fragmentos autobiográficos", Buber (1991) tem duas passagens onde ele conta experiências pessoais que se relacionam com sua concepção de religião.

Numa primeira, ele relata um encontro com um velho conhecido seu, o reverendo Hechler, que aconteceu um pouco antes da primeira guerra mundial. Nesse encontro Hechler, que era um preceptor em cortes européias, mostra a Buber uma representação gráfica da profecia de Daniel, e uma espécie de mapa do tempo histórico no qual ele pode ver, como ele mesmo o diz, $o$ ponto exato no qual nos encontrávamos precisamente então. No decorrer da conversa, Hechler anuncia, não sem uma certa solenidade: E agora venho dizer-lhe que este ano vai estourar a guerra mundial. Buber fica impressionado com a expressão guerra mundial que ele ouvira pela primeira vez. Conta também que compreendeu, mais tarde, a certeza de Hechler naquele anúncio, como uma uma interpretação crente de Daniel, (...) impregnada e concretizada pela matéria que corria nas cortes da Europa, sem que um conhe- cimento daquilo que se passava tão fundo na alma tivesse penetrado na consciência. Mais para o final do encontro Hechler, segundo a lembrança de Buber, lhe diz: Nós vivemos numa grande época. Diga-me: você crê em Deus? Buber tranquiliza o velho homem, respondendo que ele não precisava se preocupar nesse sentido. No entanto após a despedida, ficou se perguntando: Eu havia dito a verdade? Eu 'cria' no Deus ao qual Hechler se referia? O que ocorria comigo? (Buber, 1991, p.40-41). E seu relato prossegue, então, da seguinte forma:

Eu permaneci durante um longo tempo na esquina, decidido a não ir adiante antes que tivesse encontrado a resposta correta. - De repente ela me surgiu no espírito, lá onde a linguagem sempre se estrutura, surgiu sem ter sido composta por mim, palavra por palavra pronunciada. - 'Quando crerem Deus', assim soava a resposta, 'significa poder falar dele na terceira pessoa, eu não creio em Deus'. E, continuando depois de algum tempo: 'O Deus que dá a conhecer previamente a Daniel esta hora da história da humanidade, esta hora antes da 'guerra mundial', de modo que este possa determinar o lugar dela na marcha dos tempos, não é o meu Deus nem é Deus. O Deus ao qual Daniel ora em sua dor é o meu Deus, o Deus de todos'. - Ainda durante muito tempo permaneci na esquina do caminho (...) e abandonei-me, agora para além da linguagem, ao esclarecimento que havia começado (Buber, 1991, p.41).

Ele está falando aqui do verdadeiro objeto da experiência religiosa: não é objeto 
de um pensamento (embora se possa pensar nele), não é também uma fonte de conhecimentos por outras vias inacessíveis (embora possa revelar coisas), mas é um outro transcendente a quem nos dirigimos a partir de nossa dor. O encontro com o velho amigo lhe permitiu ver melhor, compreender melhor, o objeto de sua fé, e com isso fazer evoluir a consciência que tinha dele. Esse aperfeiçoamento de consciência se deu lá onde a linguagem sempre se estrutu$r a$, resignificando uma presença, e abrindo caminho para o esclarecimento que havia começado.

$\mathrm{O}$ segundo relato aparece no fragmento que se intitula "Uma conversão". Buber nos conta inicialmente as concepções que tinha. São textos mais longos mas que merecem ser citados.

$\mathrm{Na}$ mocidade o 'religioso' era para mim a exceção. Eram horas retiradas do curso das coisas. (...) $A$ 'experiência religiosa' era a vivência de uma alteridade que não encaixava no contexto da vida. (...)

Podia começar como algo habitual, a consideração de um objeto habitual, mas que bruscamente se tornava misterioso e enigmático até iluminar o caminho em direção à obscuridade atravessada de relâmpagos do próprio mistério. Mas o tempo também podia desgarrar-se sem estágios intermediários: primeiro a estrutura firme do mundo e em seguida a confiança ainda mais firme em si mesmo ficavam destruidas e a pessoa se entregava à plenitude nas asas do "religioso". Enquanto acolá estava a habitual existência com suas ocupações, aqui reinava enlevação, iluminação, êxtase, atemporal inconsequente. A única existência abrangia então um aquém e um além, e não havia nenhum vinculo senão, sempre, o instante efetivo da passagem (Buber, 1991, p.42; tradução corrigida a partir de Friedman, 1993, p.66).

Até aqui a descrição de sua experiência religiosa até então. Foi um acontecimento cotidiano, um acontecimen to orientador, que "falou" a Buber, provocando o que ele considera uma transformação. Um dia, depois de uma manhã de júbilo 'religioso', ele recebe a visita de um jovem. Ele o recebe bem, conversa atenciosa e francamente, como o fazia com os que o procuravam nessas condições. Mas talvez por causa da manhã de "júbilo religioso", ele não estava com $a$ alma presente. O conteúdo essencial das perguntas que o rapaz lhe viera trazer, ele só o soube mais tarde, por um de seus amigos, pois o jovem havia morrido logo depois do encontro com Buber. Soube que ele não havia vindo a mim acidentalmente, mas sim fatalmente, não para uma conversa amena, mas sim para uma decisão (...). O que esperamos quando estamos desesperados e mesmo assim ainda nos dirigimos a uma pessoa? Talvez uma presença através da qual nos é dito que o sentido todavia existe. O contraste entre o júbilo "religioso", note as aspas, que aconteceu logo antes dessa conversa, e a falta de alma, ou de presença, quando esteve com o moço e deixou escapar o conteúdo essencial da conversa, deve ter sido o que lhe tocou. O fato é que a partir daí houve uma mudança que ele descreve como se segue:

Desde então eu abandonei aquele 'religioso' que não é nada mais 
que exceção, retirada, saída, êxtase; ou ele me abandonou. Eu não possuo nada além do cotidiano, do qual eu nunca sou retirado. O mistério não se abre mais, ele se subtraiu ou fixou domicílio aqui, onde tudo acontece como aconteceu. Eu não conheço mais nenhuma plenitude além daquela de cada hora mortal, de exigência e responsabilidade. Longe de estar a altura dela, eu sei, porém, que sou solicitado pela exigência e posso responder à responsabilidade, e sei quem fala e quem exige resposta. - Muito mais eu não sei. Se isso é religião, então ela é simplesmente tudo, o simples todo vivido na sua possibilidade de diálogo (Buber, 1991, p.43).

Mais adiante, ele tem uma frase que cabe bem aqui: 'Fé' não é um sentimento da alma do homem, mas uma entrada na realidade, na realidade inteira, sem desconto e abreviação (Id., p.45). Para ele a experiência religiosa deixou de ser experiência de algo separado e de outro mundo, diríamos, e passou a ser a própria experiência do encontro humano ou intramundano, tornado possível em sua plenitude e profundidade dialógica. Buber exemplifica, pois, uma possível evolução da religião de cada um, ou uma depuração do sentido religioso da experiência.

\section{Considerações finais}

Não pretendo fazer exatamente uma síntese de Tomka, Vaz, Meslin e Buber. Cada um tem sua perspectiva própria, e todas elas enriquecem a descrição fenomenológica. Todos eles convergem para uma realidade. Gostaria apenas de destacar alguns pontos.
Embora a experiência religiosa sob certo aspecto se apodere da pessoa, ela só pode se desenvolver plenamente contando com sua adesão. Há aqui um paradoxo de passividade e adesão ativa, mas que justamente revela o caráter eminentemente relacional e envolvente dessa experiência.

Seu objeto é o absolutamente transcendente. Mas ele não é visto em si mesmo (e poderia?), e sim, na relação de alguma coisa do mundo (ou de si próprio) com ele. Pode tomar o aspecto, então, da percepção de uma dimensão da realidade: sua dimensão de dependência. E esta dimensão parece, para quem a vivencia, a mais determinante da realidade última das coisas. Daí, aliás, o caráter abrangente de tal experiência em termos de resignificação da vida e das coisas.

Os conceitos são aí importantes, e não apenas enquanto expressão posterior de algo já pronto. Embora haja diversidade possível de conceitos, no entanto a experiência religiosa inclui a vivência de seu significado enquanto religioso. Desse ponto de vista ela é também uma compreensão, embora num sentido bem diferente de uma compreensão meramente racional ou lógica sem referência a um real. Assim entendida, é uma experiência que tem um alcance cultural evidente. Ela influencia na organização dos significados do mundo, individual e coletivamente.

O último ponto que gostaríamos de destacar aqui, e que também é de difícil formulação, é o aspecto processual ou evolutivo dessa experiência, por mais que ela possa ter seus momentos marcantes. Os significados desses momentos, por mais que eles conservem sua força primitiva, po- 
dem, eles mesmos, se transformar ou serem incorporados em estruturas semânticas mais abrangentes, mudando assim de coloração. Em continuidade com isso, os próprios momentos marcantes podem ser de outro tipo quando vividos a partir de um referencial diferente. E a experiência, enquanto pontual, se constitui de outra forma. Mas ao mesmo tempo isso mostra que a experiência religiosa também pode ser entendida como o processo da relação. Seus momentos pontuais adquirem sentido enquanto inseridos nesse processo onde é muito difícil, aliás, determinar de forma nítida onde tudo começa ou onde tudo termina. Mas esse último fato nos diz ainda que os limites entre a inquietação religiosa e a experiência religiosa propriamente dita, podem também não ser tão nítidos assim: são certamente diferentes, mas podemos pensar numa continuidade entre os dois.

Em um próximo artigo deveremos estar apresentando a leitura fenomenológica de um depoimento concreto.

\section{Referências Bibliográficas}

Amatuzzi, Mauro m. (1996). A experiência religiosa: uma leitura de Martin Buber. Estudos de Psicologia, 13(3):63-70.

Amatuzzi, M.M.; Echeverria, D.F.; Brisola, E.B.; \& Giovelli, L.N. (1996). Psicologia na Comunidade: uma experiência. Campinas, SP. Ed.Alínea.

Buber, Martin (1984). Eclipse de Dios - estudios sobre las relaciones entre Religión y Filosofía. Buenos Aires, Nueva Visión (as conferências originais são de 1951).

Buber, M.(1991). Encontro - Fragmentos Autobiográficos. Petrópolis/RJ, Vozes.
Brugger, Walter (1987). Dicionário de Filosofia, organizado com a colaboração do corpo docente do colégio Berchmans de Pullach, Munique, e de outros professores. 4a.ed. da tradução portuguesa. São Paulo: EPU. (original alemão, 9a.ed., 1957).

Friedman, Maurice (1993). Encuentro en el desfiladero - la vida de Martin Buber. Buenos Aires: Planeta. (Traduzido do original em inglês, copyright de 1991)

Helminiak, Daniel A.(1996). Scientific spirituality: the interface of Psychology and Theology. The International journal for the Psychology of Religion, 6(1): 1-19.

Mahfoud, Miguel (1997). Uma concepção fenomenológica de experiência religiosa. In: Salus (Associação para a Saúde, Núcleo Salus Paulista) (1997), A psicologia e o senso religioso: anais do seminário. Ribeirão Preto - SP, $14 \mathrm{e}$ 15 de março, P.17-28.

Meslin, Michel (1993). A experiência humana do divino - fundamentos de uma antropologia religiosa. Petrópolis/RJ: Vozes. (Original francês, copyright de 1988)

Tomka, Miklós (1997). A fragmentação do mundo das experiências na época moderna. Concilium, 271(3):11-27 [387-403].

Valentini, Vando (1997). O senso religioso na perspectiva de Luigi Giussani. In: Salus(Associação para a Saúde, Núcleo Salus Paulista) (1997), A psicologia e o senso religioso: anais do seminário. Ribeirão Preto - SP, 14 e 15 de março, P.59-66.

Vaz, Henrique de Lima (1986). Escritos de Filosofia: problemas de fronteira. S.Paulo, ed.Loyola. 